\title{
Efeito de Exsudatos de Colônias e de Filtrados de Culturas de Actinomicetos na Eclosão, Motilidade e Mortalidade de Juvenis do Segundo Estádio de Meloidogyne javanica*
}

\author{
João L. Coimbra ${ }^{1 * *} \&$ Vicente P. Campos ${ }^{1 * *}$ \\ 'Departamento de Fitopatologia, Universidade Federal de Lavras (UFLA), Cx. Postal 37, CEP 37200-000, \\ Lavras, MG, fax (035) 3829-1283, e-mail: joaoluizcoimbra@ hotmail.com
}

(Aceito para publicação em 12/05/2005)

Autor para correspondência: João L. Coimbra

COIMBRA, J.L. \& CAMPOS, V.P. Efeito de exsudatos de colônias e de filtrados de culturas de actinomicetos na eclosão, motilidade e mortalidade de juvenis do segundo estádio de Meloidogyne javanica. Fitopatologia Brasileira 30:232-238. 2005 .

\begin{abstract}
RESUMO
Dez filtrados de culturas de actinomicetos causaram redução na motilidade e $100 \%$ de mortalidade de $\mathrm{J} 2$ de Meloidogyne javanica. A diluição de alguns causou redução de 75 a $85 \%$ de mortalidade. Contudo, o filtrado do isolado PIC 1 causou, mesmo em diluição, 100\% de mortalidade. Alguns filtrados reduziram a motilidade sem causar mortalidade. Dos isolados que causaram mortalidade também reduziram eclosão de J2. Entretanto, a porcentagem de redução variou ao longo do período de crescimento do actinomiceto em meio líquido. Exsudatos obtidos de colônias de alguns isolados de actinomicetos crescidos em meio sólido causaram $100 \%$ de mortalidade e redução na motilidade de J2 de M. javanica. Os isolados de actinomicetos ALF 4 e QUI 4 produziram substâncias tóxicas a J2 tanto em filtrado quanto em exsudato de colônia.
\end{abstract}

Palavras-chaves adicionais: nematóides de galhas, reprodução, efeito tóxico, meio líquido, exsudação.

\begin{abstract}
Effect of colony exudates and culture filtrates of actinomycetes on hatching, mobility and mortality of second stage juveniles of Meloidogyne javanica

Ten filtrates of actinomycetes cultivated in liquid medium, induced reduction of motility and $100 \%$ mortality of Meloidogyne javanica J2. Some of them, when diluted in water, reduced mortality to 75 a $85 \%$. However, the isolate PIC 1, maintened $\mathbf{J} 2$ mortality of $100 \%$, even after dilution in water. Some filtrates reduced motility, without causing mortality. Among the isolates that caused mortality, some also reduced $\mathrm{J} 2$ hatching. Nevertheless, the level of hatching inhibition varied with the growing status of the actinomycete in liquid medium. Exudates obtained from some actinomycete cultures in solid medium induced $100 \%$ mortality and reduction on motility of $\mathrm{J} 2 \mathrm{of}$ M. javanica. The isolates of actinomycetes ALF 4 and QUI 4 produced substances toxic to J2 in filtrates and in colony exudates as well.
\end{abstract}

Additional keywords: root-knot nematode, reproduction, toxic effect, broth medium, exudation.

\section{INTRODUÇÃO}

Metabólitos de microrganismos produzidos no meio em que crescem são conhecidos há muito tempo (Yarbrough et al., 1993). A função desses produtos pode ser ecológicaantagônica, inibindo o crescimento ou desenvolvimento de competidores a exemplo dos antibióticos produzidos por bactérias (Keel et al., 1990) ou mesmo promovendo associações com outros microrganismos, plantas superiores com fungos micorrízicos (Hallman \& Sikora, 1996). A indústria tem explorado comercialmente substâncias metabólicas produzidas por fungos e bactérias (Nardo \& Capalbo, 1998). Com finalidades médicas e/ou industriais essas substâncias, produzidas in vitro e/ou in vivo, têm sido estudadas no sentido de verificar supressão de patógenos de

\footnotetext{
*Parte da Tese de Doutorado do primeiro autor. Universidade Federal de Lavras (2003).

**Bolsista do CNPq
}

plantas. Por exemplo, substâncias produzidas in vitro por fungos e bactérias têm sido resportadas inibindo eclosão, afetando motilidade e causando mortalidade em fitonematóides (Costa et al., 2000).

Os actinomicetos produzem antibióticos, enzimas e inibidores enzimáticos de interesse industrial (Willians \& Vickens, 1988). Na agricultura, a avermectina produzida pelo actinomiceto Streptomyces avermitilis (Burg) Kim \& Goodfellow (Stretton et al., 1987), possui efeito nematicida já testado no controle de Meloidogyne incognita (Kofold \& White) Chitwood, Hoplolaimus galeatus (Cobb) Thorne, Tylenchulus semipenetrans (Cobb), Tylenchorhynchus dubius (Bütschli) Filipjev e Pratylenchus penetrans (Cobb) Filipjev (Garabedian \& Van Gundy, 1983; Sasser et al; Blackburn et al., 1996).

A ocorrência de actinomicetos em solos pobres e de baixo $\mathrm{pH}$, freqüentes no cerrado brasileiro (Pereira, 1995), abre perspectivas para pesquisas em rizosferas de novas 
espécies de plantas, bem como para procura de moléculas produzidas por tais organismos com possibilidades de aplicação no controle de fitodoenças, principalmente as causadas por nematóides. Dentro deste contexto, procurouse estudar o efeito de exsudatos de colônias de actinomicetos em meio sólido e filtrados de culturas em meio líquido na eclosão, motilidade e mortalidade de juvenis do segundo estádio de Meloidogyne javanica (Treub) Chitwood.

\section{MATERIAL E MÉTODOS}

\section{Obtenção de filtrados de culturas de actinomicetos e de exsudatos de colônias em meio sólido.}

Na obtenção dos filtrados dos actinomicetos estudados, utilizaram-se 41 isolados. Destes, 27 procedentes da rizosfera de culturas de interesse econômico e 14 de ervas daninhas e gramíneas forrageiras. Os isolados foram preservados em meio glicerol $10 \%$ e mantidos congelados a $-80^{\circ} \mathrm{C}$. No início do experimento, cada isolado foi transferido para placa de Petri, contendo meio de "Starch-casein-nitrate Agar" (SCN), pH 7,0-7,2 (Küster \& Williams, 1964) que foi incubada a 25 ${ }^{\circ} \mathrm{C}$ em câmara de crescimento do tipo BOD durante sete dias. Após esse período, um disco de $5 \mathrm{~mm}$ de diâmetro do meio com a cultura pura de actinomiceto foi transferido para um Erlenmeyer contendo meio líquido "malt-yeast-extract" (MYE) com a seguinte composição: extrato de malte (10 g), amido solúvel $(10 \mathrm{~g})$, dextrose $(4 \mathrm{~g})$, extrato de levedura (4 g) e pH ajustado antes da autoclavagem para 6,8. Após essa transferência, foi feita a incubação durante 14 dias, a $25^{\circ} \mathrm{C}$, em agitador orbital "shaker", a $140 \mathrm{rpm}$. Ao final desse período, as culturas foram centrifugadas a $15.000 \mathrm{~g}$ por 10 min para remoção das estruturas somáticas do actinomiceto. O sobrenadante foi individualmente colocado em frascos de vidro esterilizado do tipo penicilina, que foram mantidos em "freezer" até o início do experimento.

Num segundo experimento foram avaliados os exsudatos de 37 isolados de actinomicetos obtidos e armazenados como descrito acima. Cada isolado foi cultivado em meio SCN e, com sete dias de crescimento em placa, foi repicado para tubos de ensaio contendo o meio inclinado de aveia (OA) com a seguinte composição: aveia (30 g), agar (20 g). Em seguida, os tubos foram colocados em câmara de crescimento e mantidos à temperatura de $25{ }^{\circ} \mathrm{C}$ até completar sete dias. Em seguida, em câmara de fluxo laminar, foram adicionados $4 \mathrm{ml}$ de água destilada esterilizada em cada tubo, agitandoo num agitador de tubos durante $1 \mathrm{~min}$. Ao final dessa operação, a solução obtida foi transferida para frascos de vidro do tipo penicilina, devidamente esterilizados, e armazenados em geladeira até o início do experimento. Foram usados quatro tubos de ensaio para obter a solução de cada isolado.

\section{Obtenção e desinfestação de ovos e juvenis do segundo estádio (J2) de Meloidogyne javanica}

Os ovos foram obtidos de raízes de tomateiros (Lycopersicum esculentum Mill.) cultivar Kadá com galhas, cultivados em casa de vegetação, utilizando-se a técnica de
Hussey \& Barker (1973). Os resíduos de raízes e impurezas foram separados dos ovos pela técnica de Coolen \& D'Herde (1972). Para desinfestação dos ovos, em câmara de fluxo laminar, a suspensão foi passada numa peneira com furos de $0,021 \mathrm{~mm}$ (500 mesh) previamente desinfestada com álcool $70 \%$. Os ovos retidos na peneira foram lavados três vezes com água destilada esterilizada. Em seguida, foram colocados numa solução de pentabiótico 300 ppm por 1 min e lavados com água destilada esterilizada. Essa operação foi repetida por quatro vezes, quando então a suspensão de ovos foi colocada num Erlenmeyer estéril e armazenada para uso nos experimentos.

Os juvenis de segundo estádio de $M$. javanica foram obtidos a partir da coleta em câmaras de eclosão montadas com tela e papel poroso, colocados num funil de porcelana, onde a suspensão aquosa de ovos foi depositada. Os J2 produzidos nas primeiras $24 \mathrm{~h}$ foram descartados, sendo empregados nos ensaios apenas $\mathrm{J} 2$ com 48 a 72 h após a eclosão. Na desinfestação, a suspensão de $\mathbf{J} 2$ foi levada a uma câmara de fluxo laminar, e passada numa peneira de $0,021 \mathrm{~mm}$ (500 mesh), na qual os nematóides ficaram retidos. A peneira com os $\mathbf{J} 2$ foi imersa numa solução de hipoclorito de sódio a $0,5 \%$ durante $1 \mathrm{~min}$, e, em seguida, numa solução de pentabiótico 300 ppm por 5 min seguido de lavagem com água destilada esterilizada. Desta forma os J2 estavam prontos para uso nos experimentos.

\section{Efeito de filtrados de culturas de actinomicetos na motilidade e mortalidade de juvenis do segundo estádio (J2) de Meloidogyne javanica}

Em células de placa tipo Elisa foram colocadas 150 $\mu l$ do filtrado de actinomiceto e $50 \mu \mathrm{l}$ de uma suspensão de cerca de $25 \mathrm{~J} 2$ de $M$. javanica previamente desinfestados. As placas foram vedadas com parafilme e colocadas em câmara de crescimento a $25^{\circ} \mathrm{C}$. Após $24 \mathrm{~h}$, foi feita a avaliação, com auxílio de microscópio biológico de objetiva invertida, do número de $\mathbf{J} 2$ imóveis (não se movimentavam ou apresentavam o corpo com aspecto retilíneo ou retorcido). Realizada essa avaliação os espécimes foram retirados do filtrado e colocados em água e mantidos por $24 \mathrm{~h}$. Os J2 que permaneceram imóveis após esse período foram classificados como mortos. Dessa forma foi avaliada a porcentagem de J2 imobilizados e mortos. Foram avaliados os filtrados de 41 isolados de actinomicetos utilizando-se quatro repetições para cada tratamento. Nas testemunhas os $\mathrm{J} 2$ foram incubados em água destilada esterilizada, meio líquido MYE sem cultivo de actinomiceto e em solução de aldicarb a $100 \mathrm{ppm}$. O delineamento experimental adotado foi o de blocos inteiramente casualizados em quatro repetições. As médias dos tratamentos foram agrupadas pelo teste de Scott \& Knott (Scott \& Knott, 1974), ao nível de 5\% de significância, após transformação dos dados em arco seno $\sqrt{x / 100}$.

Efeito do filtrado de culturas de actinomicetos na eclosão de juvenis do segundo estádio (J2) de Meloidogyne javanica Montou-se uma câmara especial de eclosão com tubos 
do tipo Eppendorf. Para isto, os fundos de dois tubos foram cortados colocando-se uma tela metálica com furos de 0,025 $\mathrm{mm}$ entre os mesmos e colados. Todo o conjunto foi desinfestado após imersão em álcool $70 \%$ por 15 min. Dois mililitros de uma suspensão com 300 ovos de M. javanica previamente desinfestados foram vertidos nessa câmara. Com o auxílio de uma bomba de vácuo, a água da suspensão foi drenada para o tubo inferior e os ovos ficaram retidos na tela. A seguir, verteu-se no tubo $1 \mathrm{~mL}$ do filtrado de culturas de actinomicetos. O tubo foi então fechado com tampa rosqueada e colocado em BOD a $25^{\circ} \mathrm{C}$. Quinze dias após avaliou-se o número de $\mathrm{J} 2$ eclodidos com auxílio de microscópio. Foram testados sete filtrados de isolados de actinomicetos que reduziram a motilidade e causaram mortalidade de $\mathrm{J} 2$ de $M$. javanica. Como testemunhas, os ovos foram colocados em água de torneira, em meio líquido de extrato de malte e em solução de aldicarb a 100 ppm. Empregou-se o delineamento experimental inteiramente casualizado em quatro repetições. Usou-se o teste de Tukey ao nível de 5\% de probabilidade para comparar as médias, após transformação dos dados em arco seno $\sqrt{x / 100}$.

Efeito de exsudatos de colônias de actinomicetos na eclosão, motilidade e mortalidade de juvenis do segundo estádio (J2) de Meloidogyne javanica

Para a realização destes estudos foram utilizadas placas de Elisa esterilizadas. Para isto, $150 \mu 1$ do exsudato de colônia de actinomiceto foram colocados em cada célula da placa de Elisa, juntamente com $50 \mu \mathrm{l}$ da suspensão contendo $30 \mathrm{~J} 2$ de $M$. javanica previamente desifestados. As placas foram vedadas com parafilme e colocadas em câmara de crescimento a $25^{\circ} \mathrm{C}$. Após 24 e $48 \mathrm{~h}$ avaliaram-se, com auxílio de microscópio, as percentagens dos $\mathrm{J} 2$ imobilizados e mortos. Foram considerados mortos os J2 que, transferidos para água, não recuperaram a motilidade após $24 \mathrm{~h}$. Testaramse exsudatos de colônias de 37 isolados de actinomicetos. Como testemunhas os $\mathbf{J} 2$ foram incubados em água. O delineamento experimental adotado foi o de blocos ao acaso com quatro repetições. As médias dos tratamentos foram agrupadas pelo teste de Scott \& Knott (Scott e Knott, 1974), e diferenciadas ao nível 5\% de probabilidade, após transformação dos dados em arco seno $\sqrt{x / 100}$.

No ensaio sobre o efeito de exsudato de colônias de actinomicetos na eclosão de $\mathrm{J} 2$ empregaram-se os isolados que imobilizaram ou mataram $\mathbf{J} 2$ no ensaio anterior. Para isto, $2 \mathrm{ml}$ do exsudato de cada colônia foi colocado em placas de plástico, de 4,5 cm de diâmetro. A seguir, foram pipetados $100 \mu \mathrm{l}$ de suspensão contendo 350 ovos de $M$. javanica previamente desinfestados. Como testemunhas, a mesma quantidade de ovos foi colocada em água, em exsudato do isolado GOI 5 que não afetou $\mathbf{J} 2$ no ensaios anteriores e em solução de $100 \mathrm{ppm}$ de aldicarb. As placas foram fechadas e acondicionadas a $25^{\circ} \mathrm{C}$ em câmara de crescimento. O ensaio foi montado em delineamento inteiramente casualizado com sete exsudatos em quatro repetições. $\mathrm{O}$ experimento foi avaliado a cada $48 \mathrm{~h}$ até completar 15 dias, contando-se o número de $\mathrm{J} 2$ eclodidos em microscópio. Ao final calculouse a porcentagem de $\mathrm{J} 2$ eclodidos. A comparação entre as médias foi feita como descrito no ensaio anterior.

\section{Efeito de diluições de filtrados de cultura de actinomicetos na mortalidade de juvenis do segundo estádio (J2) de Meloidogyne javanica}

Foram selecionados cinco filtrados de actinomicetos entre os que se mostraram eficientes na redução da motilidade e no aumento da mortalidade de J2 de M. javanica. Para isto, esses filtrados foram diluídos em água destilada esterilizada nas proporções de 1:0, 1:1 e 1:2 (v/v) (filtrado: água), colocados em tubos de Eppendorf e para os quais transferiram-se, em seguida, $30 \mathrm{~J} 2$ de $M$. javanica desinfestados pelo método descrito anteriormente. Os tubos foram, então, fechados e mantidos a $25{ }^{\circ} \mathrm{C}$ em câmara de crescimento. Após 24 h, avaliou-se o número de J2 imóveis e mortos. Consideraram-se mortos os J2 que após terem sido retirados do filtrado e transferidos para água, não recuperaram a motilidade após $24 \mathrm{~h}$. Como testemunhas os J2 foram incubados em água de torneira, meio líquido MYE e em solução 100 ppm de aldicarb. O experimento foi montado em delineamento inteiramente casualizado com quatro repetições. A comparação entre as médias foi feita como descrito anteriormente.

\section{RESULTADOS E DISCUSSÃO}

Efeito de filtrados de culturas de actinomicetos na motilidade, mortalidade e eclosão de juvenis do segundo estádio (J2) de Meloidogyne javanica e estudos com diluições

A motilidade de $\mathrm{J} 2$ de $M$. javanica foi reduzida (Pd" $0,05)$ por 15 dos 41 isolados dos actinomicetos em observações comparativas às testemunhas em que os $\mathrm{J} 2$ foram incubados em água ou no meio líquido MYE. Dez filtrados reduziram a motilidade comparada ao nível $(\mathrm{Pd} " 0,05)$ da redução causada pela solução de aldicarb. Essas reduções variaram de 12 a 100\% (Tabela 1). Contudo, a mortalidade de J2 foi significativa em 11 dos 41 isolados testados, comparada às testemunhas em que os $\mathbf{J} 2$ foram incubados em água ou no meio líquido. Dos isolados que causaram mortalidade, apenas ALF 4 causou $75 \%$, os demais $100 \%$, semelhantes (Pd" 0,05) ao nível de mortalidade ocorrida na incubação de $\mathrm{J} 2$ em aldicarb (Tabela 1). A mortalidade ocorreu sempre quando houve redução na motilidade; entretanto, cinco isolados, (CAF 5, SOR 2, MAM 3, BRA 2 e BRA 3), que causaram imotilidade não ocorreu mortalidade de J2 (Tabela 1). Dos isolados estudados, 26 não reduziram a motilidade e nem causaram mortalidade: ALF 3, JIL4, CES1, ALF2, ALH3, MEL2, MIL1,QUI2,COU8, QUI1, BRA4, BRA5, COU5, ALH1, CAR1, JIL1, GRA1, MEL3, COU3, COU1CAF9, TOM1, ALF1, CEL1, MEL4, JOA1.

A ocorrência, nem sempre concomitante de imotilidade e mortalidade, indica, talvez, a presença de substâncias diversas nos diferentes filtrados provavelmente 
com modos diferentes de atuação no J2. As substâncias envolvidas na mortalidade de $\mathrm{J} 2$ parecem ser altamente tóxicas, já que causaram $100 \%$ de mortalidade, e podem ocorrer tanto na rizosfera de culturas de interesse econômico, como também nas de ervas daninhas ou gramíneas quando infestadas por esses actinomicetos. Al-Doori et al. (1991) testaram o efeito de filtrado de Streptomyces sp. produzido em meio líquido MYE sobre Toxocara canis (Werner) e constataram $100 \%$ de mortalidade do verme após dez dias da incubação no filtrado. Kasuyoshi et al. (2002) encontraram supressão da motilidade de $\mathbf{J} 2$ de $M$. incognita causada por filtrado de culturas de isolados de Streptomyces sp. após extração com acetona.

Todos os sete filtrados de isolados de actinomicetos testados reduziram significativamente a eclosão total de $\mathbf{J} 2$ de $M$. javanica comparada às testemunhas em que o $\mathrm{J} 2$ foi incubado em água ou em meio líquido MYE, porém semelhantes $(\mathrm{Pd} \leq 0,05)$ àquela em solução de Temik (Tabela 2$)$. Esses mesmos isolados causaram 75 a $100 \%$ de mortalidade de $\mathrm{J} 2$ em ensaio anterior (Tabela 1).

Uma ou mais substâncias excretadas no filtrado afetaram tanto a eclosão como a mortalidade de J2. Redução na reprodução de Caenorhabditis elegans (Smith) de 55 e $96 \%$ em três e sete dias, respectivamente, de incubação em filtrado de Streptomyces sp. foi encontrada por Dicklow et al. (1993). Esse efeito foi correlacionado pelos autores com a má formação das membranas das células germinais do

TABELA 1 - Efeito de filtrado de cultura de actinomicetos na motilidade e mortalidade de juvenis do segundo estádio (J2) de Meloidogyne javanica em $24 \mathrm{~h}$ de exposição

\begin{tabular}{|c|c|c|}
\hline \multirow{2}{*}{$\begin{array}{l}\text { Testemunhas e filtrados } \\
\text { de actinomicetos* }\end{array}$} & \multicolumn{2}{|c|}{$\begin{array}{c}\text { Juvenis do segundo estádio (J2) } \\
\text { de } M \text {. Javanica* * }\end{array}$} \\
\hline & Imóvels (\%) & Mortos (\%) \\
\hline Testemunha (MYE) & $0 \mathrm{f}$ & $0 \mathrm{c}$ \\
\hline Testemunha (água) & $0 \mathrm{f}$ & $0 \mathrm{c}$ \\
\hline Testemunha (Aldicarb) & $100 \mathrm{a}$ & $100 \mathrm{a}$ \\
\hline QUI 8 & $100 \mathrm{a}$ & $100 \mathrm{a}$ \\
\hline CAF 8 & $100 a$ & $100 \mathrm{a}$ \\
\hline CAF 5 & $100 \mathrm{a}$ & $0 \mathrm{c}$ \\
\hline PIC 1 & $100 \mathrm{a}$ & $100 \mathrm{a}$ \\
\hline QUI 4 & $100 \mathrm{a}$ & $100 \mathrm{a}$ \\
\hline GOI 5 & $100 \mathrm{a}$ & $100 \mathrm{a}$ \\
\hline QUI 6 & $100 \mathrm{a}$ & $100 \mathrm{a}$ \\
\hline MAM 1 & $100 \mathrm{a}$ & $100 \mathrm{a}$ \\
\hline JIL 5 & $100 \mathrm{a}$ & $100 \mathrm{a}$ \\
\hline CES 2 & $100 \mathrm{a}$ & $100 \mathrm{a}$ \\
\hline ALF 4 & $95 \mathrm{~b}$ & $75 \mathrm{~b}$ \\
\hline SOR 2 & $88 \mathrm{c}$ & $0 \mathrm{c}$ \\
\hline MAM 3 & $45 d$ & $0 \mathrm{c}$ \\
\hline BRA 2 & $15 \mathrm{e}$ & $0 \mathrm{c}$ \\
\hline BRA 3 & $12 \mathrm{e}$ & $0 \mathrm{c}$ \\
\hline
\end{tabular}

*Vinte e seis isolados testados não reduziram a motilidade nem causaram mortalidade.

***édias seguidas por letras distintas na coluna diferiram entre si pelo teste de Scott \& Knott a 5\% de probabilidade.

$\mathrm{MYE}=$ meio de cultura líquido extrato de malte e levedura ovário de fêmeas, além de envolver várias substâncias separadas por diálise.

Diluições em 1:1 e 1:2 de filtrados de quatro culturas de actinomicetos reduziram em aproximadamente 75 e $85 \%$ a mortalidade de $\mathrm{J} 2$, respectivamente. Contudo, essas mesmas diluições não alteraram o nível de $100 \%$ de mortalidade causada pelo isolado PIC 1 (Figura 1).

O isolado PIC 1, possivelmente, produz substâncias tóxicas a $\mathbf{J} 2$ em alta concentração ou mesmo de alto poder tóxico comparado aos demais isolados testados (Figura 1). Burg et al. (1979) isolaram a partir da fermentação do micélio de Streptomyces avermitilis (Burg) Kim \& Goodfellow uma nova classe de lactonas macrocíclicas conhecidas como avermectinas. Essas avermectinas e derivados semi-sintéticos foram eficazes contra algumas espécies de nematóides em doses extremamente baixas tendo efeito nematicida até dez vezes superior ao oxamil e aldicarb; no entanto, apresentaram baixa toxicidade em mamíferos (Garabedian \& Van Gundy, 1983).

Efeito de exsudatos de colônias de actinomicetos na motilidade, mortalidade e eclosão de juvenis do segundo estádio (J2) de Meloidogyne javanica

A motilidade de $\mathrm{J} 2$ de $M$. javanica foi reduzida ( $\mathrm{Pd}$ $\leq 0,05$ ) por quatro e seis exsudatos de colônias de actinomicetos, dos 37 testados, em incubação por 24 e 48 h, respectivamente, comparada com a verificada em água. Essa redução variou de 70 a $100 \%$. Dois isolados reduziram a motilidade em $100 \%$ semelhante (Pd" 0,05$)$ à ocorrida na solução de aldicarb (Tabela 3). Os mesmos isolados que reduziram a motilidade causaram, também, mortalidade, a qual variou de 19 a $100 \%$ quando os $\mathrm{J} 2$ foram expostos por 24 e 48 h. Os isolados ALF 4 e QUI 4 produziram substâncias tóxicas a $\mathbf{J} 2$ em filtrado de cultura (Tabela 1) e em exsudatos de colônia (Tabela 3). Trinta e um isolados dos isolados testados não causaram mortalidade e nem reduziram a

TABELA 2 - Efeito de filtrado de cultura de actinomicetos na percentagem de eclosão total de juvenis do segundo estádio (J2) de Meloidogyne javanica, após 15 dias de incubação

\begin{tabular}{lc}
\hline \hline $\begin{array}{l}\text { Testemunhas e filtrados } \\
\text { de actinomicetos }\end{array}$ & Eclosão $(\%)^{*}$ \\
\hline Testemunha ( água) & $90 \mathrm{a}$ \\
Testemunha (MYE) & $81 \mathrm{~b}$ \\
Aldicarb (100 ppm) & $1 \mathrm{c}$ \\
JIL 5 & $5 \mathrm{c}$ \\
QUI 8 & $2 \mathrm{c}$ \\
MAM1 & $3 \mathrm{c}$ \\
CAF 8 & $1 \mathrm{c}$ \\
ALF 4 & $1 \mathrm{c}$ \\
QUI 6 & $2 \mathrm{c}$ \\
PIC 1 & $3 \mathrm{c}$
\end{tabular}

*Médias seguidas por letras distintas diferiram pelo teste de Tukey a 5\% de probabilidade.

MYE - meio líquido extrato de malte 


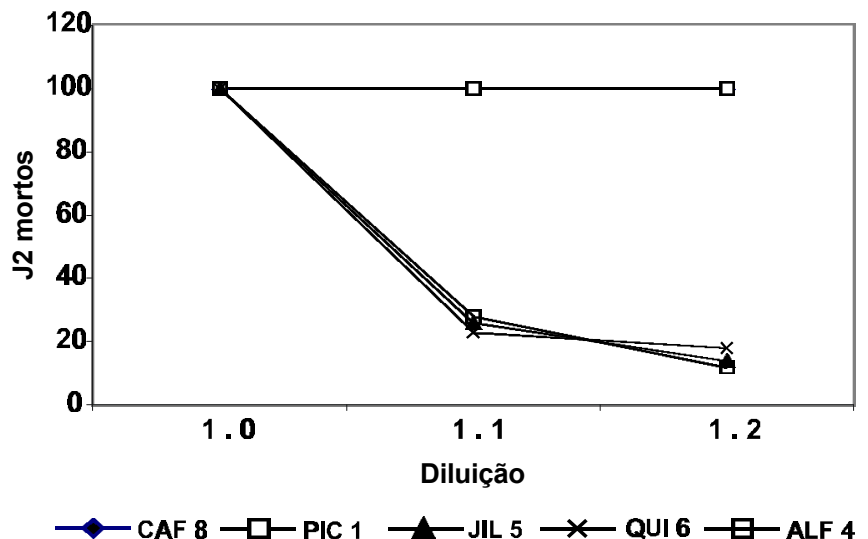

FIG. 1 - Efeito de diluições de filtrados de culturas de actinomicetos (PIC 1, JIL 5, QUI 6, ALF 4 e CAF 8) na mortalidade de juvenis de segundo estádio (J2) de Meloidogyne javanica, após $24 \mathrm{~h}$ de exposição.

motilidade: COU2, QUI6, QUI2, QUI5, ALF1, BRA1, QUI3, MAM2, COU3, CAF7, QUI7, GRA2, CES1, CAF1, CAF12, MEL3, PIC1, CAF9, CAF4, BRA5, COU10, CAF6, CEL1, CES2, SOR1, JIL4, BRA3, PIC4, MAM3, GOI5, CES9. A exposição dos $\mathrm{J} 2$ por $48 \mathrm{~h}$ aumentou a mortalidade comparada àquela em 24 h (Tabela 3 ).

A obtenção de substâncias antagônicas a fitonematóides de colônias de actinomicetos crescidas em meio sólido pode facilitar a seleção de isolados, bem como a purificação dessas substâncias, pois não estariam misturadas a ingredientes do meio de cultura, como ocorre quando se cultiva em meio líquido.

A exsudação de colônias tem sido estudada em bactérias. Balota et al. (1995) extraíram exsudatos de colônias de bactérias diazotróficas após centrifugação da cultura em meio líquido e ressuspensão do precipitado em água. Esse

TABELA 3 - Efeito de exsudatos de colônias de actinomicetos na percentagem de motilidade e mortalidade de juvenis do segundo estádio (J2) de Meloidogyne javanica após 24 e 48 h de exposição

\begin{tabular}{|c|c|c|c|c|}
\hline \multirow{2}{*}{ Tratamento* } & \multicolumn{2}{|c|}{24 h de exposiçãa ${ }^{* *}$} & \multicolumn{2}{|c|}{$48 \mathrm{~h}$ de exposiçãa** } \\
\hline & $\begin{array}{c}\text { Imóvels } \\
(\%)\end{array}$ & $\begin{array}{c}\text { Mortos } \\
(\%)\end{array}$ & $\begin{array}{c}\text { Imbvels } \\
(\%)\end{array}$ & $\begin{array}{c}\text { Mortos } \\
(\%)\end{array}$ \\
\hline Test (á gua) & $0 \mathrm{e}$ & $0 \mathrm{e}$ & $0 \mathrm{e}$ & $0 \mathrm{~d}$ \\
\hline Test ( Aldicarb) & $100 \mathrm{a}$ & $100 \mathrm{a}$ & $100 \mathrm{a}$ & $100 \mathrm{a}$ \\
\hline ALF 2 & $100 a$ & $100 \mathrm{a}$ & $100 a$ & $100 \mathrm{a}$ \\
\hline SOR 3 & $91 \mathrm{~b}$ & $19 d$ & $100 a$ & $64 c$ \\
\hline BRA 4 & $79 c$ & $32 \mathrm{c}$ & $77 \mathrm{~d}$ & $66 \mathrm{c}$ \\
\hline ALF 4 & $70 \mathrm{~d}$ & $71 \mathrm{~b}$ & $82 d$ & $80 \mathrm{~b}$ \\
\hline QUI 4 & $0 \mathrm{e}$ & $0 \mathrm{e}$ & $83 \mathrm{~b}$ & $84 \mathrm{~b}$ \\
\hline $\mathrm{CAF} 2$ & $0 \mathrm{e}$ & $0 \mathrm{e}$ & $79 \mathrm{c}$ & $82 \mathrm{~b}$ \\
\hline
\end{tabular}

*Os demais 31 isolados testados não reduziram a motilidade e nem causaram mortalidade sendo atribuído o valor 0 .

**Médias seguidas por letras distintas nas colunas diferiram pelo teste de Scott \& Knott a $5 \%$ de probabilidade. exsudato bacteriano diminuiu o crescimento micelial do fungo micorrízico Gigaspora gigantea (Nicol. \& Gerd.) Gerd \& Trappe. Park et al. (2002) observaram 50 a $90 \%$ de redução da motilidade de $C$. elegans em 3 e 6 h de incubação, respectivamente, quando colocados diretamente na colônia do actinomiceto Streptoverticillium albireticuli (Nakasawa) Witt \& StacKebrandt cultivado em placas de Petri por sete dias no meio FMEA.

Entre os quatros isolados que reduziram, significativamente, a eclosão de $\mathrm{J} 2$ de $M$. javanica (Tabela 4), o CAF 2 e ALF 2 proporcionaram sempre menor eclosão do que a testemunha em qualquer período de avaliação (Figura 2 A,B). O ALF 4 apenas no oitavo dia teve eclosão igual da testemunha nos demais períodos a eclosão sempre foi menor (Figura 3 B). Entretanto, o SOR 3 teve eclosão abaixo da
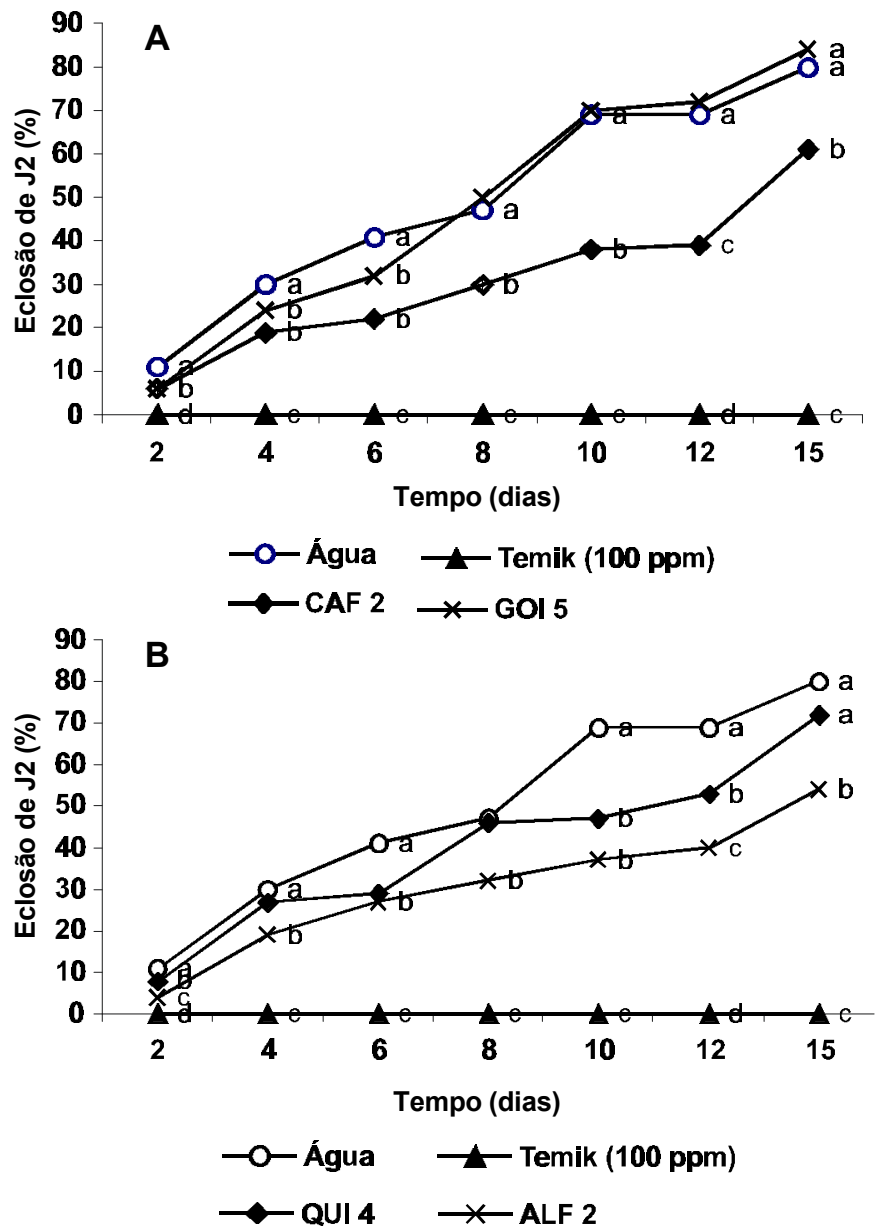

FIG. 2 - Progresso da eclosão de juvenis do segundo estádio (J2) de Meloidogyne javanica nos exsudatos de colônias dos isolados A) CAF 2 e GOI 5, B) QUI 4 e ALF 2 que causaram efeito na motilidade e mortalidade de $\mathrm{J} 2 \mathrm{em}$ ensaio anterior durante 15 dias de incubação. O GOI 5 foi usado como comparativo entre aqueles que não afetaram os J2. Também a incubação em água e aldicarb a 100 ppm serviram-se de testemunhas. Letras minúsculas diferentes em cada ponto da curva indicam diferença estatística a 5\% pelo teste de Scott \& Knott (Scott e Knott, 1974). 
TABELA 4 - Efeito dos exsudatos de colônias de actinomicetos que afetaram a motilidade e causaram mortalidade de juvenis do segundo estádio em ensaio anterior, na eclosão total de J2 de Meloidogyne javanica após 15 dias de incubação

\begin{tabular}{cc}
\hline $\begin{array}{l}\text { Testemunha efiltrados } \\
\text { de actinomicetos }\end{array}$ & Eclosão* (\%) \\
\hline Testemunha ( água) & $80 \mathbf{a}$ \\
Aldicarb (100 ppm) & $0 \mathrm{c}$ \\
CAF 2 & $61 \mathbf{b}$ \\
GOI 5 & $84 \mathbf{a}$ \\
QUI 4 & $72 \mathbf{a}$ \\
SOR 3 & $62 \mathbf{b}$ \\
ALF 2 & $54 \mathbf{b}$ \\
ALF 4 & $57 \mathbf{b}$ \\
BRA 4 & $83 \mathbf{a}$ \\
\hline
\end{tabular}

*Médias seguidas por letras distintas diferiram pelo teste de Scott \& Knott a $5 \%$ de probabilidade.
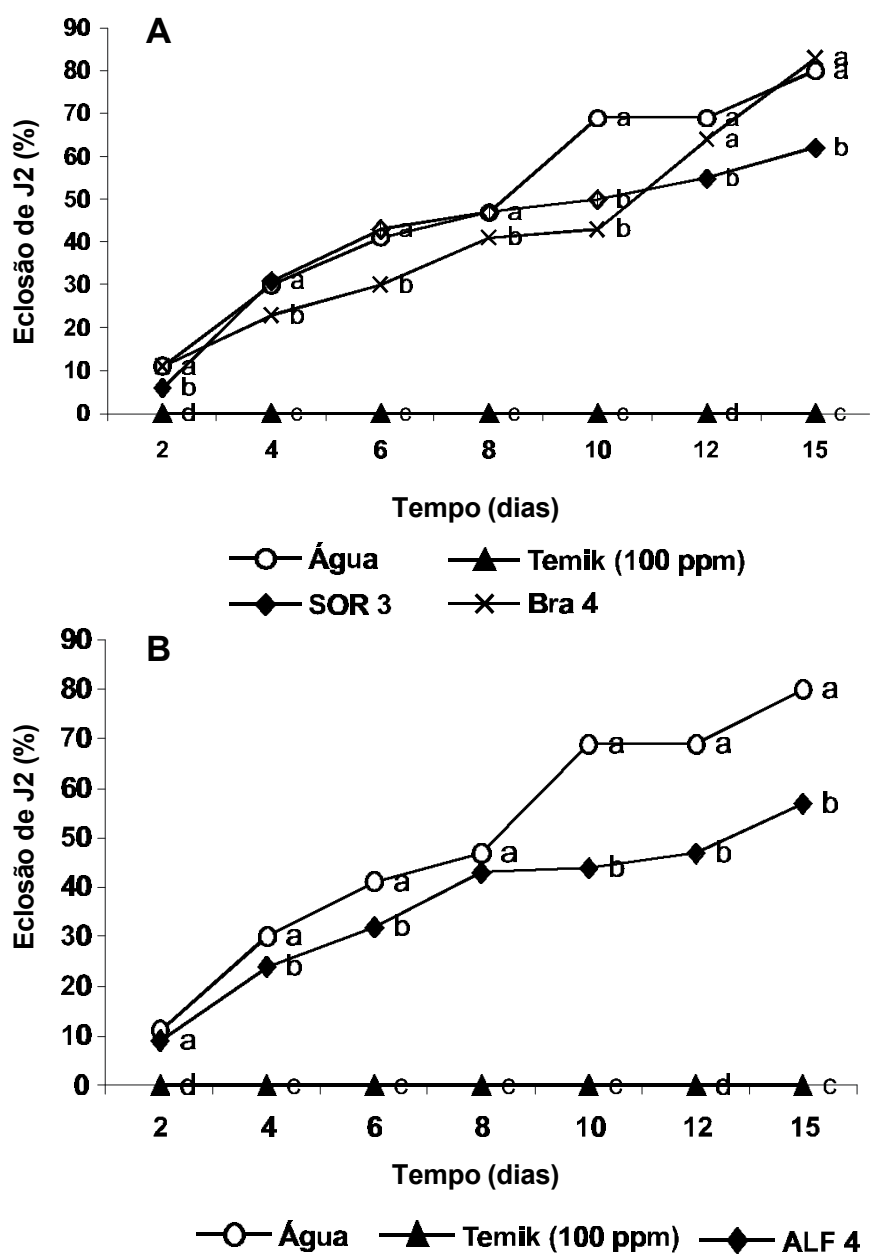

FIG. 3 - Progresso da eclosão de juvenis do segundo estádio (J2) de Meloidogyne javanica nos exsudatos de colônias dos isolados: A) SOR 3 e BRA 4, B) ALF 4 e controle que causaram efeito na motilidade e mortalidade de $\mathrm{J} 2 \mathrm{em}$ ensaio anterior durante 15 dias de incubação. A incubação em água e aldicarb a 100 ppm serviramse de testemunhas. Letras minúsculas diferentes em cada ponto da curva indicam diferença estatística no nível de 5\% pelo teste de Scott \& Knott (Scott e Knott, 1974). testemunha apenas a partir do décimo dia de incubação (Figura 3 A). Nos demais isolados (BRA 4, GOI 5 e QUI 4) a eclosão de $\mathrm{J} 2$ foi sempre próxima a da testemunha (Figura 3 A) e (Figura 2 A,B).

Para o isolado SOR 3, talvez, o efeito da toxina tenha ocorrido apenas nos eventos iniciais do desenvolvimento embrionário; desta forma os ovos com juvenis formados ou mesmo no estádio avançado do desenvolvimento embrionário prosseguiram até a eclosão, sem retardamento comparado à testemunha. Já nos isolados CAF 2, ALF 2 e ALF 4, o efeito foi semelhante em qualquer fase do desenvolvimento embrionar.

A constatação de efeito tóxico dos isolados ALF2 e BRA 4 sobre $\mathrm{J} 2$ de $M$. javanica a partir de exsudatos de colônias, porém com ausência nos filtrados, talvez, seja decorrente da produção de substâncias tóxicas, apenas, após a esporulação em meio sólido.

\section{REFÊRENCIAS BIBLIOGRÁFICAS}

AL-DOORI, M., AL-TAE, A.A., JALIL, S. \& HASSAN, S.A. Larvicidal activity of actinomycetes isolates against Toxocara canis. Folia Parasitologica 38:379-832. 1991.

BALOTA, E.L., LOPES, E.S., HUNGRIA, M. \& DÖBEREINER, J. Interações e efeitos fisiológicos de bactérias diazotróficas e fungos micorrízicos arbusculares na mandioca. Pesquisa Agropecuária Brasileira 30:1335-1345. 1995.

BLACKBURN, K., ALM, S.R. \& YEH, T.S. Avermectin B1, izafos, and fenamiphos for control of Hoplolaimus galeatus and Tylenchorhynchus dubius infesting Poa annua. Journal of Nematology 48:687-694. 1996.

BURG, R.W., MILLER, B.M., BAKER, E.E., BIRNBAUN, J., CURRIE, S.A., HARTMAN, R., KONG, Y.L., MONAGHAN, R.L., OLSON, G., PUTTER, I., TUNAC, J.B., WALLICK, H., STAPLEY, E.O., OIWA, R. \& OMURA, D. Avermectins, a new family of potent anthelmintic agents: Producing organisms and fermentation. Antimicrobial Agents. Chemotherapy 15:361-367. 1979.

COOLEN, W.A. \& D'HERDE, C.J. A method for the quantitative extraction of nematodes from plant tissue. Ghent: State Agriculture Research Centre, 1972.

COSTA, M.J.N., CAMPOS, V.P., PFENNING, L.H., OLIVEIRA, D.F. Patogenicidade e reprodução de Meloidogyne incognita em tomateiro (Lycopersicon esculentum) com aplicação de filtrados fúngicos ou extratos de plantas e de estercos animais. Nematologia Brasileira 24:219-226. 2000.

DICKLOW, M.B., ACOSTA, N. \& ZUCKERMAN, B.M. A novel Streptomyces species for controlling plant-parasitic nematodes. Journal of Chemical Ecology 19:159-173.1993.

GARABEDIAN, S. \& VAN GUNDY, S.D. Use of avermectin for the control of Meloidogyne incognita on tomatoes. Journal of Nematology 15:503-510. 1983.

HALLMAN, J. \& SIKORA, R.A. Toxicity of fungal endophyte secondary metabolites to plant parasitic nematodes and soilborne plant pathogenic fungi. European Journal of Plant Pathology 102:155-162. 1996.

HUSSEY, R.S. \& BARKER, K.R. A comparison of methods for colecting inocula of Meloidogyne spp. Including a new technique. 
Plant Disease Reporter 57:1025-1028. 1973.

KAZUYOSHI, C., FURUKAWA, M., FUKUDA, S., SHOJI, M., YANAGISAWA, T., HIDEO. I., TERUO, S. \& AKIRA, N. Suppressive effects of antinematodal Streptomyces spp.on root-knot nematodes of cucumbers caused by Meloidogyne incognita. Biocontrol Science 7:25-29. 2002.

KEEL, C., WIRTHNER, P.H., OBERHANSLI, T.H., VOISARD, C., BURGER, U., HAAS, D. \& DEFAGO, G. Pseudomonads as antagonists of plant pathogens in the rhizosphere: role of antibiotic 2,4-diacetylphloroglucinol in the suppression of black root rot of tobacco. Symbiosis 9:327-342. 1990.

KÜSTER, E. \& WILLIAMS, S.T. Selection of media for the isolation of streptomycetes. Nature 202:928-929. 1964.

NARDO, E.A.B. \& CAPALBO, D.M.F. O processo de avaliação de risco do uso de agentes microbianos de controle: testes ecotoxicológicos sobre organismos não visados. Arquivos do Instituto Biológico 59:63-68. 1998.

PARK, J.O., EL-TARABILY, K.A., GHISALBERTI, E.L. \& SIVASITHAMPARAM, K. Pathogenesis of Streptoverticillium albireticuli on Caenorhabditis elegans and its antagonism to soilborne fungal pathogens. Letters in Applied Microbiology 35:361365. 2002.

PEREIRA, J.C. Ecologia da comunidade bacteriana em solos de cerrado. (Tese de Doutorado). Itaguaí. Universidade Federal Rural do Rio de Janeiro. 1995.

POLLAK, F.C. \& BERGER, R.G. Geosmin and related volatiles in bioreactor-cultured Streptomyces citreus CBS 109.60. Applied and Environmental Microbiology 62:1295-1299.1996.

SASSER, J.N., KIRKPATRICK, T.L. \& DYBAS, R.A. Efficacy of avermectins for root-knot control in tobacco. Plant Disease 66:691693. 1982.

SCOTT, A.J. \& KNOTT, M. A cluster analysis method for grouping means in the analysis of variance. Biometrics 30:507-512. 1974.

STRETTON, A.O.W., CAMPBELL, W.C. \& BABU, J.R. Biological activity and mode of action of avermectins. In: Veech, J.A. \& Dickson, D.W. (Eds.) Vistas on Nematology: A Commemoration of the Twenty-fifth Anniversary of the Society of Nematologists. 1987. pp.136-146.

WILLIANS, S.T. \& VICKENS, J.C. Detection of actinomycetes in the natural environment-problems and perspectives. In: Okani, Y., Bepper, T. \& Ogawara, H. (Eds.) Biology of the Actinomycetes 88. Tokyo, 1988. pp.265-270.

YARBROUGH, G.G., TAYLOR, D.P., ROWLANDS, R.T., CRAWFORD, M.S. \& LASURE, L.L. Screening microbial metabolites for new drugs: theorical and practical issues. The Journal of Antibiotics 46:535-544. 1993. 